\title{
Betti Teoremi ile Plaklar ve Dönel Kabuklar için Genelleştirilmiş Sonlu Fark Çözümü
}

\author{
Nahit KUMBASAR ${ }^{1}$
}

ÖZ

Son y1llarda üzerinde çok çalışılan ve düzgün bir ağ gerektirmeyen ağsız yöntemler, genelleştirilmiş sonlu fark yönteminin geliştirilmiş şekilleridir. Bu çalışmada ince elastik plaklar ve dönel kabuklara uygulanabilen, Betti teoremi kullanılarak elde edilmiş, genelleştirilmiş bir sonlu fark çözüm yöntemi sunulmaktadır.

Anahtar Kelimeler: Sonlu fark yöntemi, ağsız yöntemler, sayısal çözümleme, Betti teoremi.

\begin{abstract}
A Generalized Finite Difference Method for Plates and Rotational Shells, Using Betti's Theorem

Meshless methods, which have been extensively studied in last decades, are essentially improved forms of the generalized finite difference method. In this paper a generalized finite difference method for thin elastic plates and rotational shells, obtained by using Betti's reciprocal theorem, is presented.
\end{abstract}

Keywords: Finite difference method, meshless methods, numerical solution, Betti's theorem.

\section{GíRiş}

Sayısal çözüm yöntemlerinden sonlu farklar yöntemi, türevlerin elde edilme biçimi nedeni ile, düzgün bir ağ gerektirir. Son yıllarda yayınlanan geliştirilmiş sonlu fark yönteminde, amaçlanan nokta çevresinde yeterli sayıda, gelişigüzel yerleşmiş nokta koordinatları cinsinden üretilen enterpolasyon fonksiyonu yardımı ile türevler ağsız nokta düzeni için de elde edilebilmektedir. Çözülmesi amaçlanan probleme bağlı olarak denklemlerin elde edilmesi, kolokasyon yöntemi, en küçük kareler yöntemi, Galerkin yöntemi vb. yöntemlerle yapılmaktadır. Son yıllarda ağsız yöntemler konusu üzerinde çok sayıda çalışma ve yayın yapılmıştır.

Not: Bu yazı

- Yayın Kurulu'na 13.04.2016 günü ulaşmış̧ır.

- 31 Aralık 2017 gününe kadar tartı̧̧maya açıktır.

- DOI: $10.18400 /$ tekderg. 335585

1 İstanbul Teknik Üniversitesi, İnşaat Müh. Bölümü, İstanbul (Emekli) - kumbasarn@itu.edu.tr 
Orkisz vd. [1] de, ağsız sonlu fark yönteminin adımları verilerek formülasyon için uygulanan değişik yöntemlerle ilgili kaynaklar belirtilmiştir. Huerta vd [2] de ağsız yöntemlerin sabit ağ yöntemlerine üstünlüğü, hangi tür problemlerde üstün oldukları açıklanmış, ağsız yöntemler iki gruba ayrılarak, birincide daha çok kolokasyon ve nokta entegrasyonu yöntemi kullanılırken ikinci grupta daha çok Galerkin yönteminin uygulandığı belirtilmiştir. Gavete ve Gavete [3] te, genelleştirilmiş sonlu fark yöntemine ağsız yöntem de dendiği belirtilerek genelleştirilmiş sonlu fark yöntemi açıklanmıştır. Idelson [4] te ağlı ve ağsız yöntemlerin üstünlük ve eksiklikleri belirtilip hangi durumda kullanılmaları gerektiği incelenmiş, standart bir kişisel bilgisayarda, artan bilinmeyen sayısı ile hesaplama zamanları kıyaslanmıştır. Belytsko [5] te, bazı problemlerde sonlu eleman, sonlu hacim gibi yöntemlerin yetersiz kaldıkları belirtilerek ağsız yöntemlerin esasında bulunan ağırlık fonksiyonu, diğer adı ile pencere fonksiyonu anlatılmış, yöntemler süreksizlik ve tutarlılık açısından irdelenmiştir. Liu ve $\mathrm{Gu}$ [6] da, ağsız yöntemlerin sorunları belirtildikten sonra, bunların giderilmesine yönelik olarak nokta entegrasyonu olarak adlandırdıkları yöntem anlatılmış, iki sayısal örnekte kıyaslamalar yapılmıştır. Bustamente vd. [7] de iki boyutlu lineer elastisite problemleri için, elastisitenin özel çözümleri birleştirilerek elde edilen yaklaşık yerdeğiştirme ifadesi ağsız yöntem için uygulanmış, her bir denklem için bölgeyi belirleyen şekil parametresinin geniş bir bölgedeki değerleri için iyi bir yaklaşım verdiği belirtilmiştir. Gu [8] de, ağsız yöntemlerin kategorileri anlatılmış, yöntemler yakınsama, yaklaşıklık ve etkinlik açısından karşılaştırılmıştır. Ülkemizde de bu konuda yayınlar vardır. Pekedis ve Yıldız [9] da, ağsız yöntemler hakkında bilgi verilmiş sonlu eleman yöntemi ile karşılaştırılmış, ağsız yöntemler formülasyon esası ve çözüm yöntemi açılarından sınıflandırılmıştır. Yine Pekedis ve Yıldız [10] da, ağsız Galerkin yöntemi lineer elastik dolu kesitli çubuklara uygulanarak etkin ve güvenilir bir yöntem olduğu ifade edilmiştir. Erdayı [11] Yüksek Lisans tezinde Petrov-Galerkin yöntemini uygulamış, ankastre çubuk ve delikli sonsuz plak çözümlerinde, entegral ve etki tanım parametrelerinin çözüme etkisini araştırmıştır. Çakıroğlu [12] Birinci Mekanik Kongresi’nde sunduğu bir çalışmada, kayma plağı ve iki boyutlu akım problemleri için değişken katsayılı ikinci mertebe kısmi türevli diferansiyel denklemlerin çözümünü incelemiştir. Söz konusu bildiride ortogonal ve iki doğrultuda farklı bir sonlu fark ağı için kayma rijitliği her aralıkta farklı olan bir kayma plağı için Betti teoremi yardımı ile bir sonlu fark operatörü elde edilmiştir. Kumbasar [13], XII Ulusal Mekanik kongresinde sunduğu çalışmasında, ayni yöntemi uygulayarak ortogonal olmayan bir ağ için bir sonlu fark operatörü elde etmiştir.

\section{YÖNTEM}

Çözüm yönteminde Betti karşıtlık teoremi kullanılmaktadır. Bilindiği gibi bu teorem, doğrusal elastik bir sisteme etkiyen iki yükleme durumunda birincinin ikinciye ait yerdeğiştirmelerde yaptığı işin ikincinin birinciye ait yerdeğiştirmelerde yaptığı işe eşit olduğunu ifade eder. $\mathrm{Bu}$ amaçla kullanılacak iki yükleme durumundan biri ilgili bilinmeyenin seçilen bir sekizgen alan içinde sınırlanmış, diğer bölgelerde sıfır olan etkileridir. İkinci yükleme durumu bilinen dış yükler ve aranan yerdeğiştirmelerdir.

Yöntemin açıklanması için önce basık kabuğa ait bağıntılar özetle verilecektir. Kabuk kesit zorlarının 
$N_{x}=K\left[u^{\prime}-\frac{w}{R_{x}}+v\left(\dot{v}-\frac{w}{R_{y}}\right)\right]$

$N_{y}=K\left[\dot{v}-\frac{w}{R_{y}}+v\left(u^{\prime}-\frac{w}{R_{x}}\right)\right]$

$N_{x y}=K \frac{1-v}{2}\left(\dot{u}+v^{\prime}\right)$

$M_{x}=-D\left(w^{\prime \prime}+\ddot{w}\right)$

$M_{y}=-D\left(\ddot{w}+v w^{\prime \prime}\right)$

$M_{x y}=-D(1-v) \dot{w}^{\prime}$

$Q_{x}=-D \Delta^{\prime}$

$Q_{y}=-D \Delta^{\prime}$

ifadelerinde $f^{\prime}$ ve $\dot{f}$ o fonksiyonun $x$ ve $y$ ye göre türevlerini, $N_{x}, N_{y}, N_{x y}$ mambran kuvvetleri, $M_{x}, M_{y}, M_{x y}$ eğilme ve burulma momentlerini, $Q_{x}, Q_{y}$ kesme kuvvetlerini, $u, v$ ve $w, \mathrm{x}, \mathrm{y}, \mathrm{z}$ doğrultularında yerdeğiştirmeleri, $\Delta w$ nin Laplace türevini göstermektedir. $K$ ve $D$, sırası ile, birim genişlikli kabuğun uzama ve eğilme rijitlikleridir.

Kesit zorlarının yukarıdaki ifadeleri, denge denklemlerinde yerine konarak, burada ayrıntısı verilmeksizin, aşağıdaki dört bağıntı elde edilir.

$$
\begin{aligned}
& u^{\prime \prime}+\frac{1-v}{2} \ddot{u}+\frac{1+v}{2} \dot{v}^{\prime}-\left(\frac{1}{R_{x}}+\frac{v}{R_{y}}\right) w^{\prime}+\frac{h^{2}}{12 R_{x}} \Delta^{\prime}=-\frac{p_{x}}{K} \\
& \ddot{v}+\frac{1-v}{2} v^{\prime \prime}+\frac{1+v}{2} \dot{u}^{\prime}-\left(\frac{1}{R_{y}}+\frac{v}{R_{x}}\right) \dot{w}+\frac{h^{2}}{12 R_{y}} \dot{\Delta}=-\frac{p_{y}}{K} \\
& \left(\frac{1}{R_{x}}+\frac{v}{R_{y}}\right) u^{\prime}+\left(\frac{1}{R_{y}}+\frac{v}{R_{x}}\right) \dot{v}-\left(\frac{1}{R_{x}{ }^{2}}+\frac{2 v}{R_{x} R_{y}}+\frac{1}{R_{y}{ }^{2}}\right) w-\frac{h^{2}}{12} \nabla^{2} \Delta=-\frac{p_{z}}{K}
\end{aligned}
$$


Betti Teoremi ile Plaklar ve Dönel Kabuklar için Genelleştirilmiş Sonlu Fark Çözümü

$\nabla^{2} w-\Delta=0$

Çözüm alanı içindeki her noktada, yakın çevresindeki sekiz nokta ile birlikte meydana getirdikleri sekizgende, aranan fonksiyonun ( $\mathrm{u}, \mathrm{v}, \mathrm{w}$ vb.) yayılışının, bu dokuz noktadaki değerleri cinsinden

$$
\begin{aligned}
& f(x, y)= \\
& f_{1}+f_{2} x+f_{3} y+f_{4} x^{2}+f_{5} x y+f_{6} y^{2}+f_{7} x^{2} y+f_{8} x y^{2}+f_{9} x^{2} y^{2}
\end{aligned}
$$

șeklinde ifade edilebileceği kabul edilmiștir (SSekil 1). Bu, ağsız yöntem deyimi ile, dokuz noktalı bir yıldız tanımına karşı gelir. Diğer yandan, yerdeğiștirme ve iç kuvvet değişimleri sadece bu sekizgen içinde kalan birim yerdeğiştirmelerin tanımlanması, entegral işlemlerini kolaylaştırması açısından önemlidir. $u, v$ ve $w$ için Şekil 2 de verilen sekizgen piramit biçimli birim yerdeğiştirme bu koşulu sağlar.

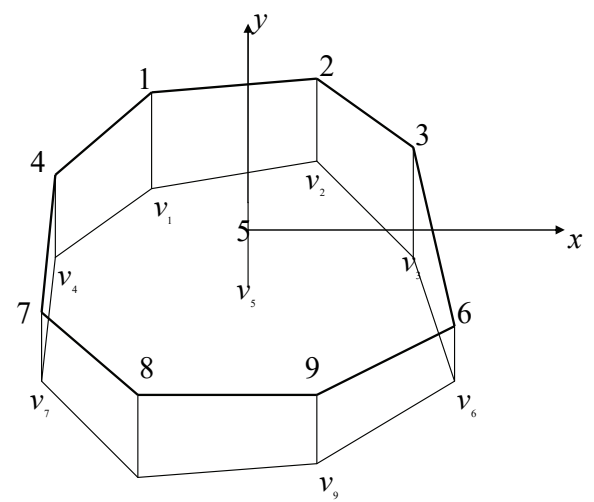

Şekil 1. Dokuz nokta için yerdeğiştirmeler

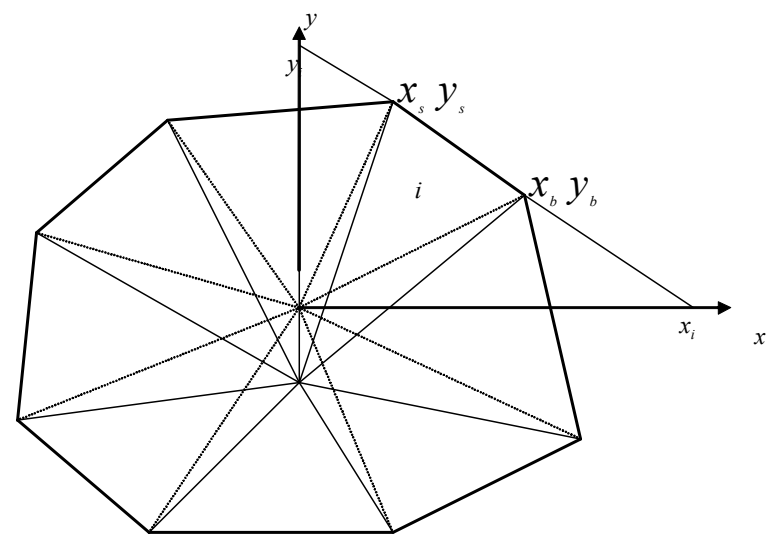

Şekil 2. Sekizgen piramit şeklinde birim yerdeğiştirme 
Alışılmış plak denkleminde türevler dördüncü mertebeden olduğundan uygulanamayan bu yöntem, Markus'tan beri bilinen, simültane iki ikinci mertebe denklemle uygulanabilir duruma gelmektedir. Denge denklemlerinde (11) bağıntısı, kabuk eğrilikleri ile ilgili terimler bir yana bırakılırsa, (12) ile birlikte düşünüldüğünde plak denklemine karşı gelir.

Şekil 2 deki birim yükseklikli sekizgen piramit birim yerdeğiştirme için kullanıldığında herbir üçgende düzlemin denklemine gereksinim olacaktır. Örneğin $i$ inci üçgen için bu denklemin, $i$ inci kenarın eksenleri kestiği noktalar, $x_{i}, y_{i}$ lere bağlı olarak

$z=1-\frac{x}{x_{i}}-\frac{y}{y_{i}}$

olduğu kolayca görülür. Bu nedenle önce her noktaya karşı gelen sekizgen için kenarların $x, y$ eksenlerini kestiği $x_{i}, y_{i}$ noktaları hesaplanıp biriktirilir.

Yukarıdaki (14) ifadesinin birim $u$ yerdeğiştirmesi için olduğunu düşünelim. Betti teoreminde kullanılacak yük için

$u_{i}=1-\frac{x}{x_{i}}-\frac{y}{y_{i}}$

ifadesinin türevleri alınarak (9)-(12) denklemlerinde yerine konduğunda yayılı yük olarak sadece $z$ doğrultusunda

$$
\frac{K}{x_{i}}\left(\frac{1}{R_{x}}+\frac{v}{R_{y}}\right)
$$

düzgün yayılı yükü bulunur. $\mathrm{R}_{\mathrm{x}}$ ve $\mathrm{R}_{\mathrm{y}}$ nin bu sekizgen içinde sabit kaldığı kabul edilecektir. $\mathrm{Bu}$ türevler (1)-(3) te yerine konduğunda

$$
N_{x}=-\frac{K}{x_{i}}, N_{y}=-v \frac{K}{x_{i}}, N_{x y}=-\frac{K}{2 y_{i}}(1-v)
$$

mambran kuvvetlerinin oluştuğu görülür. Üçgenden üçgene değişen, fakat her üçgen içinde sabit olan bu kuvvetlerin üçgen kenarlarında, $s i$ ve $c o$ o kenara ait normalin doğrultu kosinüsleri olmak üzere $x$ doğrultusunda

$q_{x x}=-K\left(\frac{c o}{x_{i}}+\frac{(1-v) s i}{2 y_{i}}\right)$

ve $y$ doğrultusunda 
$q_{x y}=-K\left(\frac{\nu s i}{x_{i}}+\frac{(1-v) c o}{2 y_{i}}\right)$

çizgisel yükü bulunur. Benzer işlemler birim $v$ yerdeğiştirmesi için uygulanarak $z$ doğrultusunda

$\frac{K}{y_{i}}\left(\frac{1}{R_{y}}+\frac{v}{R_{x}}\right)$

düzgün yayılı yükü ve $x$ doğrultusunda

$q_{y y}=-K\left(\frac{s i}{y_{i}}+\frac{(1-v) c o}{2 x_{i}}\right)$

ve $y$ doğrultusunda

$q_{y x}=-K\left(\frac{v c o}{y_{i}}+\frac{(1-v) s i}{2 x_{i}}\right)$

çizgisel yükleri elde edilir. Bu yükler sekiz üçgenin herbirinde elde edilip Betti teoremi gereği elde edilmesi amaçlanan $u$ ve $v$ yerdeğiştirmeleri ile çarpılarak entegre edilecektir.

Üçüncü doğrultuda hesap daha önce belirtildiği gibi iki kademelidir. Önce (12) denklemi göz önüne alınırsa, ifade kayma rijitliği birim olan ve $\Delta$ yükü etkisinde bir kayma plağının diferansiyel denklemidir. Burada da yük niteliğinde olan $\Delta$ nın birim şiddetinde sekizgen piramit biçiminde olduğu düşünülecektir. Yine her bir üçgen bölümünde yükün ifadesi bir düzlem denklemi gibidir. Doğrusal olan bu ifadenin ikinci türevleri sıfir olduğundan yayılı yük yoktur. Buna karşılık, çökmenin birinci türevleri sıfır değildir, kayma rijitliği birim olduğundan bu türevlere eşit kesme kuvvetleri ve üçgen kenarları üzerinde bunların bileşkesi olan çizgisel $q_{z}$ düzgün yayılı yükleri oluşur:

$q_{z}=-\frac{c o}{x_{i}}-\frac{s i}{y_{i}}$

bu yükler aranan $\mathrm{w}$ ile çarpılarak entegre edilecektir. Bu birim $w$ nin $x, y, z$ doğrultularına karşı gelen düzgün yayılı yükleri (9), (10) ve (11) denklemlerinden ve $x$ e göre türevin -1/xi ve $y$ ye göre türevin $-1 / y_{i}$ olduğu hatırlanarak

$q_{z x}=-\frac{K}{x_{i}}\left(\frac{1}{R_{x}}+\frac{v}{R_{y}}\right)$ 
$q_{z y}=-\frac{K}{y_{i}}\left(\frac{1}{R_{y}}+\frac{v}{R_{x}}\right)$

$q_{z z}=K\left(1-\frac{x}{x_{i}}-\frac{y}{y_{i}}\right)\left(\frac{1}{R_{x}^{2}}+\frac{2 v}{R_{x} R_{y}}+\frac{1}{R_{y}^{2}}\right)$

olduğu görülür. (11) denklemindeki $\nabla^{2} \Delta=\frac{p_{z}}{D}$ için de benzer işlem uygulanır.

Elde edilen çizgisel ve yayılı yüklerden, $q_{z z}$ dışında tümü sabit değerdedir. Gerekli olan entegrasyon işlemi sayısal entegrasyon yöntemi ile yapılabilirse de burada daha etkin ve doğru değer vereceği düşünülen bir yöntem uygulanmıștır. Çizgisel yüklerin entegrali, bütün noktalar için geçerli olan (13) enterpolasyon fonksiyonunun bir katının, koordinatları bilinen iki nokta arasında entegrali anlamındadır. $\mathrm{Bu}$ fonksiyonun katsayıları çevre noktaların koordinatlarına bağlı olduğundan noktadan notaya değişir. Bu nedenle, kapalı bir ifade olarak elde edilmesi amaçlanan bu entegral (13) ifadesinin her bir terimi için ayrı ayrı hesaplanarak ilgili nokta için olan katsayı ile çarpılarak toplanmalıdır. Sözkonusu $1, x, x^{2}, x y, \ldots x^{2} y^{2}$ terimlerinin entegrali alınarak bir alt programa konmuştur. Üzerinde entegral alınan kenarın başlangıç ve son nokta koordinatları $\left(x_{b}, y_{b}\right),\left(x_{s}, y_{s}\right)$ e (Şekil 2) bağlı olan bu entegral ifadelerinin, enterpolasyon ifadesinin dördüncü terimi $x^{2}$ için olanı örnek olarak verilirse, el ilgili kenarın uzunluğu ve

$x_{o 2}=\left(x_{b}^{2}+x_{b} x_{s}+x_{s}^{2}\right) / 3$ olmak üzere

$e n(4)=e l \times x_{o 2}$

şeklindedir.

Çizgisel yüklerin dışında, alana yayılı yükler de elde edilmiştir. Bu yüklerin, (13) le tanımlanan yerdeğiştirme ile çarpımının entegrali de nokta koordinatlarına bağlı bir kapalı ifade olarak elde edilebilir. Her nokta grubu için yerel koordinatlar sekizgenin iç noktası başlangıç seçilerek hesaplanmış ve enterpolasyon fonksiyonu bu koordinatlar cinsinden elde edilmiştir. Yayılı yüke ait hacim entegrali bu yerel koordinatlar cinsinden sekiz üçgenin her biri için hesaplanıp toplanır. Örneğin enterpolasyon fonksiyonunun birinci sabit terimi ve dördüncü $x^{2}$ terimi için bu entegraller, uç nokta koordinatları $a=x_{b}, \quad b=x_{s}$, $c=y_{b}, d=y_{s}$ olmak üzere

$$
\begin{aligned}
& a l=(a \times d-b \times c) / 2 \\
& x_{k}(1)=a l / 3 \\
& x_{k}(4)=a l \times\left(a^{2}+a \times b+b^{2}\right) / 30
\end{aligned}
$$

şeklindedir. Sözü edilen entegraller MathLab veya Mathematica gibi yardımcı programlarla hesaplanabilir. Burada ikinci program kullanılmıştır. 
Betti teoreminde birinci yükleme durumu olarak alınan her birim yerdeğiştirmede hesaplanan bu iş, karşı gelen diş yükün bu birim yerdeğiştirme üzerinde yaptığ 1 işe eşittir. Her noktada, sözkomusu olan yerdeğiştirmelerin herbiri için, yukarıda belirtilen işlemlerle Betti teoremi uygulanarak, klasik sonlu fark yönteminde olduğu gibi, bilinmeyen sayısı kadar denklem elde edilerek çözülür.

\section{SINIR KOȘULLARI}

Bu çözüm yönteminde, doğal sınır koşulları, $u, v, w$ ve $\Delta$ nın var veya sıfır oluşu ile ifade edilir. Klasik sonlu fark yönteminde sınır koşulları, gerekli türev ifadeleri yerine sonlu fark ifadeleri konarak gerçekleştirilir. Burada, iç noktalar için açıklanan yöntem, sınırda sıfır olmayan yerdeğiştirmeler için de uygulanarak gerçekleştirilecektir. $\mathrm{Bu}$ nedenle iç noktalarda sekizgen piramit için elde edilmiş olan entegral ifadeleri sınırda üçgen piramit için elde edilmiştir. Basit mesnet dişında bir sınır söz konusu olduğunda, yukarıda sözü edilen sekizgen piramit yerine, sınırdaki yerdeğiştirmeyi temsil eden üçgen piramit kullanılmalıdır. Sınır koşulları için bu biçimde tanımlanan yerdeğiştirmelere ait alan entegralleri ayrıca hesaplanıp bir alt programa yerleştirilmiştir.

\section{4. ÖRNEKLER}

Yöntemin etkinliğini belirtmek üzere, noktaların bir karesel ağ oluşturmadığı dört örnek, üçgen plak, dairesel plak, silindirik kabuk ve küresel kabuk örnekleri ile yakınsamayı görmek üzere basit mesnetli kare plak çözümleri yapılmıştır.

\section{Örnek 1. Ü̧̧gen plak}

Girkmann [14] da kapalı çözüm ifadesi verilen basit mesnetli eşkenar üçgen plakta, çökmenin ve eğilme momentlerinin en büyük olduğu noktalarda değerler hesaplanarak kaynakta verilen değerlerle karşılaştırılmıştır.

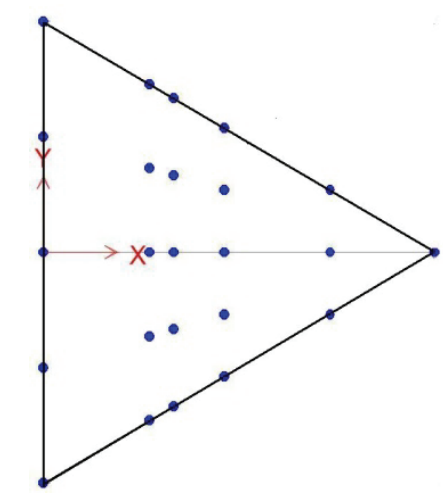

Şekil 3. Üçgen plakta nokta dă̆llımı 
Tablo1. Üçgen plak için karşılaş̧tırma

\begin{tabular}{|l|c|c|c|}
\hline Büyüklük & {$[14]$} & Bulunan & Hata \% \\
\hline $\mathrm{wD} / \mathrm{pa}^{4}$ & 0.001029 & 0.001080 & 5 \\
\hline $\mathrm{M}_{\mathrm{x}} / \mathrm{pa}^{2}$ & 0.0248 & 0.0214 & 15.9 \\
\hline $\mathrm{M}_{\mathrm{y}} / \mathrm{pa}^{2}$ & 0.0259 & 0.0212 & 22.2 \\
\hline
\end{tabular}

Düzgün yayılı $p$ yüküne maruz, basit mesnetli eşkenar üçgen plağın en büyük çökme değeri ağırlık merkezinde, en büyük $M_{x}$ ve $M_{y}$ değerleri iki ayrı noktada hesaplanmıştır. Bu noktaların apsisleri ağırlık merkezinden $-0.062 a$ ve $0.129 a$ mesafededir. Tablo $1 \mathrm{de}$, burada hesaplanan değerler [14] te verilenlerle karşılaştırılmıştır. Az sayıda nokta ile elde edilen sonucun yeterli olduğu söylenebilir.

$\mathrm{Bu}$ örnekte Şekil 3 te görülen 10 iç nokta için işlemler olabildiğince ayrıntılı olarak verilmeye çalışılacaktır. Sonlu fark denklemlerinin yazılması amaçlanan noktaya en yakın sekiz nokta seçilerek Şekil 2 deki gibi dokuz noktalı bir bölge oluşturulur. Başlangıçları söz konusu nokta olan yerel koordinat eksenlerinde ifade edilen enterpolasyon fonksiyonu dokuz noktanın koordinatları ile yazılarak elde edilen dokuz denkleme ait katsayılar matrisinin tersi hesaplanır.

Sekizgeni oluşturan her bir üçgende, enterpolasyon fonksiyonunun her bir terimi için, dış kenar koordinatlarına bağlı alan entegrali ve üçgen kenar uç koordinatlarına bağlı çizgisel entegraller hesaplanıp bir diziye yerleştirilir. Üçgen piramit biçiminde seçilen birim yer değiştirme için her bir üçgende bu çökmeyi oluşturan dış yük enterpolasyon fonksiyonu ile ifade edilen çökme ile çarpılacaktır. Plak probleminde ikinci mertebe iki kayma plağı diferansiyel denklemi söz konusu olduğundan düzlem yüzeylerin eğimleri ile orantılı olan kesme kuvvetleri oluşur. Üçgenin her bir kenarının doğrultusuna bağlı Sin ve Cos değerleri cinsinden bu kesme kuvveti $-\left(\operatorname{Cos} / x_{k}+\operatorname{Sin} / y_{k}\right)$ olarak elde edilir. $x_{k}$ ve $y_{k}$ üçgen dış kenarının yerel koordinat eksenlerini kestiği değerlerdir. Bu kesme kuvvetinin çökme ifadesinin terimleri ile çarpımının entegreli önceden hesaplanmış entegraller yardımı ile elde edilir. Her bir terim için sekiz üçgen üzerinde hesaplan entegraller toplanarak dokuz elemanlı bir diziye yerleștirilir. Bu dizi, sözü edilen ters matrisle çarpılarak sekizgenin her bir noktasındaki çökme ile ilgili entegral bulunmuş olur; bu sonlu fark denkleminin sol tarafıdır. Sağ taraf için de benzer içlemler yapılır. (12) denkleminde $\Delta$ için de să̆ taraf işlemi uygulanmakla birlikte aranan bilinmeyen olması nedeni ile yeri denklemin soludur.

\section{Örnek 2. Dairesel plak}

Şekil 4 te görülen dairesel plakta da noktalar karesel bir ağ oluşturmamaktadır. Bu plağın çözümü için sınır koşulu olarak, $\Delta=0, \quad w=0$ doğal sınır koşulları alınacaktır. Bu sınır koşulları basit mesnet koşullarından farklı sonuçlar verir. Plak ortasında çökme $3 p a^{4} / 64 D$ ve eğilme momentleri $(1+v) p a^{2} / 8$ değerini alırlar. $v=0.20$ için yapılan çözümde elde edilen sonuçlar Tablo 2 de verilmiştir. 


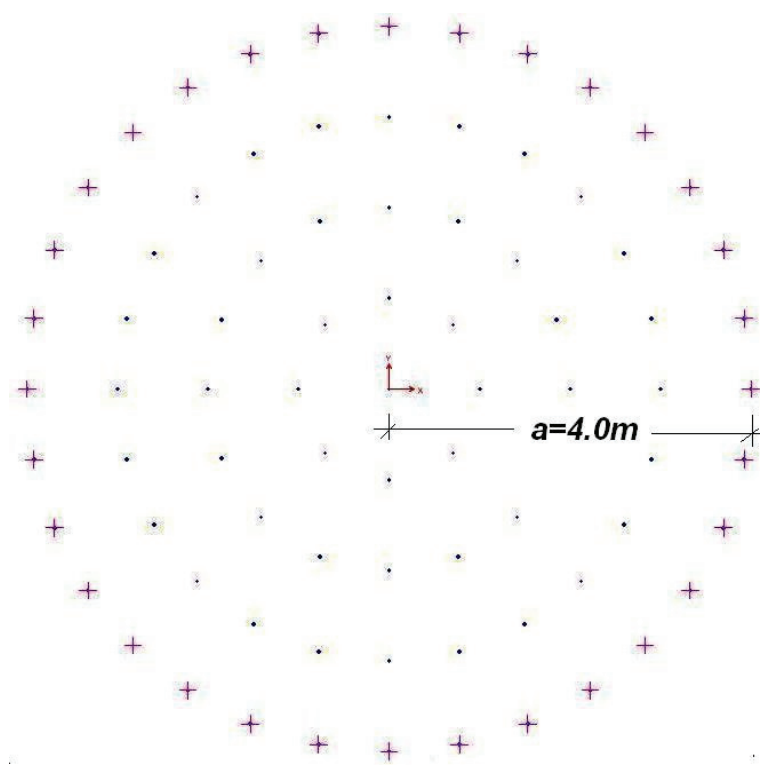

Şekil 4. Dairesel plakta nokta dă̆ılımı

Tablo 2. Dairesel plak için karşılaş̧ırma

\begin{tabular}{|l|c|c|c|}
\hline Büyüklük & Teorik & Bulunan & Hata \% \\
\hline $\mathrm{wD} / \mathrm{pa}^{4}$ & 0.04688 & 0.04656 & -0.7 \\
\hline $\mathrm{M}_{\mathrm{x}} / \mathrm{pa}^{2}$ & 0.15 & 0.1458 & -2.8 \\
\hline $\mathrm{M}_{\mathrm{y}} / \mathrm{pa}^{2}$ & 0.15 & 0.1458 & -2.8 \\
\hline
\end{tabular}

\section{Örnek 3. Kare plak}

Nokta düzeninin etkisini görmek üzere kare bir plak önce $7 \times 7$ düzgün karesel ağla çözülmüş, sonra nokta sayısı ayni kalmak üzere Şekil 5 te verilen gelişigüzel bir nokta dağılımı için çözülerek sonuçlar karşılaştırılmıştır. Plak orta noktasında boyutsuz çökme ve eğilme momenti değerleri Tablo3 te karşılaştırılmıştır. Düzenli nokta dağılımının gerçeğe daha yakın sonuç verdiği görülmektedir.

Tablo 3. Kare plak için karşılaştırma

\begin{tabular}{|l|c|c|c|c|c|}
\hline Büyüklük & Teorik & Düzenli nokta & Hata \% & Düzensiz & Hata \% \\
\hline $\mathrm{wD} / \mathrm{pa}^{4}$ & 0.004062 & 0.004063 & 0.02 & 0.004063 & 0.02 \\
\hline $\mathrm{M}_{\mathrm{x}} / \mathrm{pa}^{2}$ & 0.0475 & 0.0439 & 8.2 & 0.0426 & 11.5 \\
\hline $\mathrm{M}_{\mathrm{y}} / \mathrm{pa}^{2}$ & 0.0475 & 0.0439 & 8.2 & 0.0404 & 17.6 \\
\hline
\end{tabular}


Nahit KUMBASAR

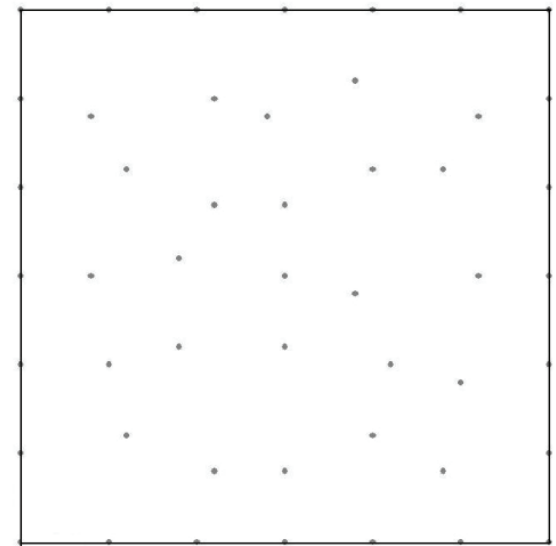

Şekil 5. Kare plakta düzensiz nokta dă̆ılımı

\section{Örnek 3. Silindirik kabuk}

Şekil 6 da şeması verilen silindirik kabuk alt ve üst çemberinde basit mesnetli ve birim değerde iç basınç taşımaktadır. Modellemede yarıçap $10.0 \mathrm{~m}$ yükseklik $24.0 \mathrm{~m}$ alınmıştır. Şekilde görülen oldukça sade nokta dağılımı ile elde edilen yerdeğiştirmeler daha sık noktalı bir ağla $(48 \times 13)$ yapılan sonlu eleman çözüm sonuçları ile karşılaştırılmış

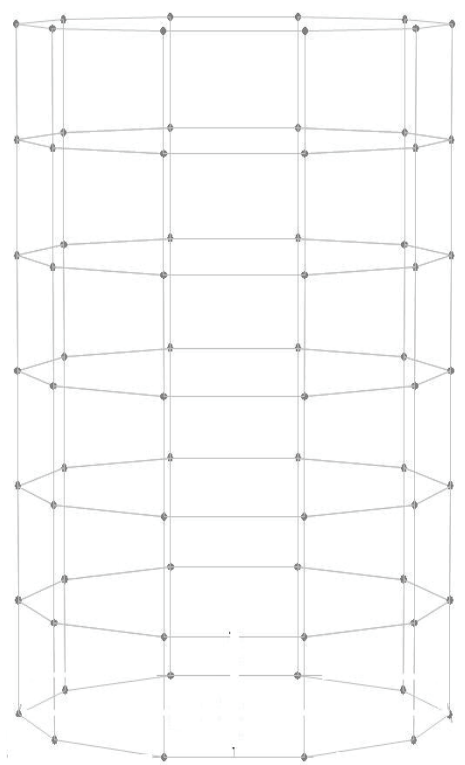

Şekil 6. Silindirik kabukta nokta dağıllş̧ı 
Betti Teoremi ile Plaklar ve Dönel Kabuklar için Genelleştirilmiş Sonlu Fark Çözümü

Tablo 4. Silindirik kabukta karşılaştırma

\begin{tabular}{|l|c|c|c|}
\hline Değer & Sonlu eleman & Bulunan & Hata \\
\hline Birinci halka $w E h / p a^{2}$ & 1.032 & 1.076 & 4.3 \\
\hline İkinci halka $w E h / p a^{2}$ & 0.876 & 0.953 & 8.8 \\
\hline Üçüncü halka $w E h / p a^{2}$ & 0.938 & 0.968 & 3.2 \\
\hline
\end{tabular}

\section{Örnek 4. Küresel kabuk}

Şekil 7 de şeması verilen yarım küre kabuk alt çemberinde basit mesnetli ve birim değerde iç basınç taşımaktadır. Modellemede yarıçap $10.0 \mathrm{~m}$ kalınlık $0.10 \mathrm{~m}$ alınmıştır. Kalınlık/yarıçap oranı 1/100, kabuk ince olduğundan mesnet etkileri hızla sönecek ve tepe noktasında mambran etkiler elde edilmesi gerekecektir. $\mathrm{Bu}$ değerler, $N \varphi=N \theta=p a / 2$, $w=p a^{2}(1-v) / 2 E h$ olarak bilinmektedir (15).
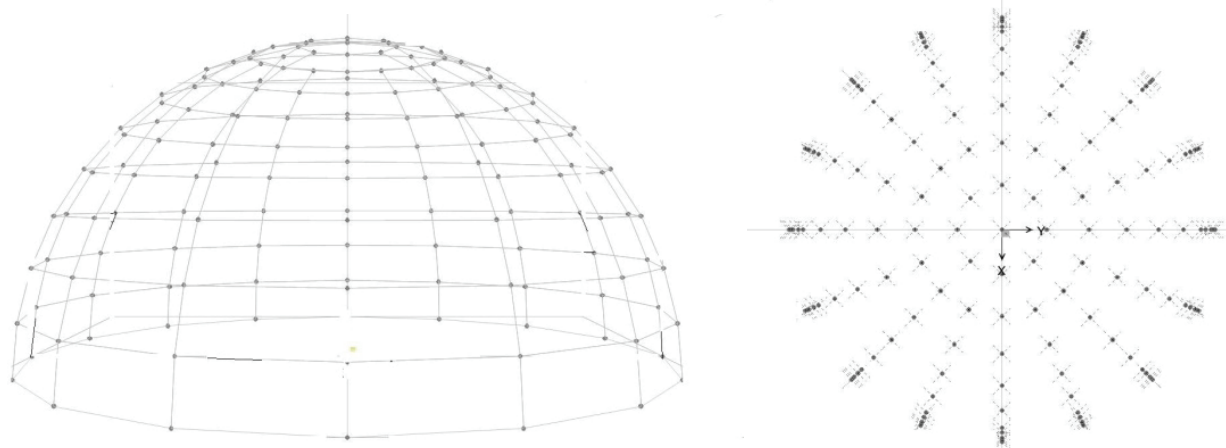

Şekil 7. Küresel kabukta nokta dağılımı görünüş ve planı

Tablo 5. Küresel kabukta karşılaştırma

\begin{tabular}{|l|c|c|c|}
\hline Değer & Teorik $(v=0.2)$ & Bulunan & Hata \% \\
\hline Tepede $w E h / p a^{2}$ & 0.400 & 0.399 & -0.3 \\
\hline Tepede $N \varphi / p a$ & 0.500 & 0.496 & -0.8 \\
\hline Tepede $N \theta / p a$ & 0.500 & 0.497 & -0.6 \\
\hline
\end{tabular}

\section{SONUÇLAR}

Geliştirilmiş sonlu fark yöntemi için, kaynak yayınlarda uygulanan yöntemden farklı olarak, Betti teoreminden yararlanan bir algoritma uygulanmıştır. Bu algoritma karteziyen koordinatlarda tanımlanmış ince plak ve levhalar için olduğu gibi, koordinatları asal eğrilikler doğrultusunda tanımlanmış ince kabuklar için de uygulanabilir. Sunulan örnekler yöntemin yaklaşımının yeterli olduğunu göstermektedir. 
Yerdeğiştirme parametreleri olarak bu çalışmada uygulanan $u, v, w$ ve $\Delta$ yerine $u, v, w$ yerdeğiştirmeleri ile, $\alpha$ ve $\beta$ dönmeleri seçilerek, yöntemin kalın plak ve kabuklara da uygulanması çalışmanın bir ileri aşaması olarak düşünülmektedir.

\section{Semboller}

$\begin{array}{ll}a & : \text { Açıklık, yarıçap } \\ D & : \text { Plak, kabuk rijitliği } \\ h & : \text { Plak, kabuk kalınlı̆̆ı } \\ K & : \text { Kabuk uzama rijitliği } \\ M_{x}, M_{y} & : \text { Eğilme momentleri } \\ N_{x}, N_{y} & : \text { Kabuk mambran kuvvetleri } \\ p_{x}, p_{y}, p_{z}, & : x, y, z \text { doğrultusunda yükler } \\ q_{x x}, q_{x y} q_{y x} q_{y y} & : \text { Birim yerdeğişstirmeden üçgenlerde oluşan düzgün yayılı yükler } \\ R_{x}, R_{y} & : \text { Kabuk ĕgrilik yarıçapları } \\ u, v, w & : x, y, z, \text { doğrultularında yerdeğiştürmeler } \\ x, y, z & : \text { Koordinatlar } \\ x_{i}, x_{i}: & : \text { Üçgen dış kenarlarının koordinat eksenlerini kesim noktaları } \\ v & : \text { Poisson oranı } \\ \Delta & : \text { w nin Laplace türevi }\end{array}$

\section{Kaynaklar}

[1] Orkisz J., Jaworska I., Magiera J., Milewski S. , Pazdanowski M. Meshless Finite Difference Method-State of the Art. 11th World Congress on Computational Mechanics (WCCM XI) July 20 - 25, 2014, Barcelona, Spain

[2] Huerta A., Belytschko T., Fernnandez-Mendez, S. , Rabczuk, T. Meshfree Methods. Encyclopedia of Computational Mechanics. Edited by Erwin Stein, Renée de Borst and Thomas J.R. Hughes. John Wiley \& Sons, Ltd. 2004

[3] Gavete, L., Gavete, M.L., Benito J.J., Improvements of generalized finite difference method and comparison with other meshless method, Applied Mathematical Modelling 27 831-847, 2003.

[4] Idelsohn, S.R, Oñate, E., To mesh or not to mesh. That is the question. Comput. Methods Appl. Mech. Engrg. 195, 4681-4696, 2006

[5] Belytschko T., Krongauz Y.., Organ, D., Fleming, M., Krysl, P. Meshless Methods An Overview and Recent Developments, Comput. Methods Appl. Mech. Engrg. 139, 3-47, 1996 
Betti Teoremi ile Plaklar ve Dönel Kabuklar için Genelleştirilmiş Sonlu Fark Çözümü

[6] Liu, G. R., Gu, Y. T., A point interpolation method for two-dimensional solids, Int. J. Numer. Meth. Engng; 50:937-951, 2001

[7] Bustamante, C.A. Power, H., Floreza W.F. , Hang, C.Y. , The global approximate particular solution meshless method for two-dimensional linear elasticity problems. International Journal of Computer Mathematics, 90, 978-993, 2013.

[8] Gu, Y. T.,Meshfree Methods and Their Comparisons, International Journal of Computational Methods, 2, 4, 477-515, 2005

[9] Pekedis, M., Yıldız, H., Ağsız Yöntemler ve Sinıflandırılması, Pamukkale Üniversitesi Mühendislik Bilimleri Dergisi 16, 1-9, 2010

[10] Pekedis, M., Yıldız, H., Eksenel Yüklü Ankastre Çubuğun Davranışının Eleman Bağımsız Galerkin Yöntemiyle Çözülmesi Pamukkale Üniversitesi Mühendislik Bilimleri Dergisi 15, 353-361, 2009

[11] Erday1, D. C. Meshless Local Petrov-Galerkin Method For Plane Elasticity Problems A Thesis Submitted To The Graduate School of Natural and Applied Sciences of Middle East Technical University, February 2014.

[12] Çakıroğlu, A. Yapı sistemleri için genel bir ayrık sistem hesap yöntemi. Birinci Ulusal Mekanik Kongresi, 1979.

[13] Kumbasar, N. Dik kenarlı olmayan dörtgen alanda Betti teoremi ile elde edilmiş bir sonlu fark yöntemi. XII Ulusal Mekanik Kongresi, Konya, 595-603, Eylul 2001.

[14] Girkmann, K. (Tameroğlu, S.S), Yüzeysel Taşıyıcı Sistemler C.1, İ.T.Ü. Kütüphanesi, Matbaa Teknisyenleri Basımevi , İstanbul 1964.

[15] Keskinel, F.,Kumbasar, N. Sürekli Temeller ve Dönel Kabuklar. İ.T.Ü. Mühendislik Mimarlık Fakültesi, Matbaa Teknisyenleri Koll. Şti., 1976

[16] Markus, H. Die Theorie elastischer Gewebe und ihre anwendung auf die Berechnung biegesamer Platten unter besonderer Berücksichtigung der traegerloser Pilzdecken. J.Springer, 1924. 